\title{
Complejo Arquitectónico Cerro Mercachas: arquitectura y ritualidad incaica en Chile central
}

\author{
Andrés Troncoso *, Daniel Pavlovic*, Félix Acuto**, \\ Rodrigo SÁncheZ*, A. César GonZÁleZ-García*** \\ * Departamento de Antropología, Facultad de Ciencias Sociales, Universidad de Chile \\ atroncos@uchile.cl daniel.pavlovic@gmail.com rsanchez@uchile.cl \\ ** Instituto Multidisciplinario de Historia y Ciencias Humanas, CONICET (Argentina) \\ facuto@gmail.com \\ *** Instituto de Ciencias del Patrimonio, Consejo Superior de Investigaciones Científicas (España) \\ a.cesar.gonzalez-garcia@incipit.csic.es
}

Recibido: 2 de agosto de 2011

Aceptado: 3 de febrero de 2012

\begin{abstract}
RESUMEN
Se discute la dinámica de la ocupación del Tawantinsuyu en la zona central de Chile a partir del estudio de la instalación más extensa ubicada en la zona: el Complejo Arquitectónico Cerro Mercachas. A partir de un análisis intra-sitio se reconoce una organización lineal y tripartita del asentamiento, lo que sumado al escaso registro de cultura material mueble llevan a proponerle una función ritual relacionada con las festividades del calendario metropolitano inca asociadas, al menos, a la observación del solsticio de diciembre y el culto al cerro Aconcagua. El contexto sugiere un uso esporádico y por pocos sujetos del sitio, implicando una ritualidad exclusiva para ciertos personajes. A una escala regional, la alta visibilidad del sitio hace que esta ritualidad se inserte en el paisaje cotidiano de las poblaciones locales, reproduciendo estrategias de construcción social del espacio que el Tawantinsuyu aplica en otras áreas. A través de ella se crea una diferencia y jerarquización con los otros espacios rituales locales, estableciendo una estrategia de integración y exclusión entre el Tawantinsuyu y las poblaciones locales. A partir de estos resultados, se discute el modelo administrativo tradicionalmente utilizado para entender la ocupación inca en la zona.
\end{abstract}

Palabras clave: Chile central, arquitectura inca, paisaje, ritual.

\section{Architectonical Complex of Cerro Mercachas: Architecture and Inca Rituality in Central Chile}

\begin{abstract}
In this paper we discuss Inca occupation in the central zone of Chile, through the study of the biggest imperial site so far known in the area: the architectonical complex of Cerro Mercachas. An intra-site analysis was able to identify a linear and tripartite spatial organization of the site. Together with the scarce material culture identified, we suggest a ritual function for this site, related to festivities surrounding Inca metropolitan calendar or, at least, the observation of the December solstice and the Cerro Aconcagua cult. The overall archaeological context suggests a sporadic use of the site and by a limited number of individuals. This implies an exclusive ritualism for a selected few. Seen at a regional level, the high visibility of the site integrates this exclusive ritualism into the daily landscape of local populations, thereby reproducing the strategies of social construction of space that Tawantinsuyu executes in other areas. This new spatial order creates difference and hierarchy with local ritual spaces, thereby materializing a strategy of integration and exclusion between Tawantinsuyu and local populations. With these results we discuss the administration model traditionally used to understand Inca occupation in Central Chile.
\end{abstract}

Key words: Central Chile, Inca architecture, landscape, ritual.

Sumario: 1. Introducción. 2. La cuenca superior del río Aconcagua y el Complejo Arquitectónico Cerro Mercachas. 3. Contextos materiales y prácticas sociales. 4. Dinámica espacial y arquitectónica del Complejo Arquitectónico Cerro Mercachas. 5. Dinámica espacial del Complejo Arquitectónico Cerro Mercachas en su contexto regional. 6. Conclusiones. 7. Referencias bibliográficas. 


\section{Introducción}

La ocupación y dominación incaica en sus diferentes provincias no sólo fue efectuada por un conjunto de comunidades asociadas al Tawantinsuyu, sino también a partir del accionar de los conjuntos de cultura material, los cuales, a través de su incorporación, distribución, utilización y descarte, fueron elementos activos en la vida social pretérita, jugando un papel preponderante en la materialización de formas simbólicas asociadas a la ideología incaica y en la conformación material de una realidad social (Acuto 2005; Coben 2006; Morris 1990, 1995). Por medio de esa materialización, ciertos principios del pensamiento incaico, y de su ideología, se plasmaron no sólo en el territorio, sino también en su operación e integración en prácticas sociales específicas que produjeron y reprodujeron tales principios. Varios autores ya reconocieron la centralidad de los «Inca-media» en este proceso (p.e. Hyslop 1986; Morris 1990, 1995; Ogburn 2004), destacando el relevante papel que tenía la arquitectura en contraposición a otras materialidades que han sido más investigadas y enfatizadas, como la alfarería (p.e. Morris 1995; Niles 1992).

A la luz de ello, este trabajo tiene como finalidad discutir y evaluar la dinámica de la arquitectura inca en la ocupación de un sector particular de Chile central, la cuenca superior del río Aconcagua, la que si bien se encuentra próxima a la frontera meridional del Estado, tiene un variado registro material asociado a la presencia del Tawantinsuyu. Para tales efectos, nos centraremos en el estudio del sitio incaico más extenso de toda la zona central de Chile, el Complejo Arquitectónico Cerro Mercachas (en adelante CACM), efectuando una discusión en dos escalas complementarias que permiten avanzar desde la dinámica de las prácticas sociales en un espacio específico a su integración dentro de un paisaje político particular que se relaciona con las formas y estrategias por medio de las cuales se estableció la ocupación de este territorio.

En una micro-escala abordamos la investigación sobre la organización intra-espacial del CACM, para definir la estructuración formal del espacio construido que materializa en este lugar principios básicos de la cosmología incaica, a la vez que posibilita y estructura las formas que adquieren las prácticas sociales allí ejecutadas. A través de ambos se establecen y reproducen significados asociados a un espacio que se plasman en prácticas sociales que se deben entender dentro de tal contexto.

En una macro-escala abordamos la integración del sitio a un nivel regional, discutiendo como CACM se integra con los restantes asentamientos de la localidad para semantizar el espacio local e integrarse en las dinámicas del habitar de las comunidades asentadas en la cuenca superior del río Aconcagua.

Esta aproximación se basa en reconocer a la arquitectura como una materialidad significante que estructura y está estructurada por la dinámica de las prácticas sociales y los mundos simbólicos de las comunidades prehispánicas (Ashmore y Sabloff 2002; Criado y Mañana 2003; Moore 1996b). Es ella un dispositivo espacial que estructura las prácticas sociales y les da un sentido en su actuación (Coben 2006; Moore 1996a, 1996b). A partir de las visibilidades asociadas, la proxémica espacial y la organización de los recorridos internos se establecen sentidos que permiten acercarnos a comprender los tipos de prácticas efectuadas en el lugar, así como al modo 
en que se articulan dentro de un contexto regional más amplio. De esta manera, tales características se constituyen en un recurso relevante para la construcción social de la realidad y la conformación de estrategias políticas, orientación que ya ha sido recogida por diferentes autores para otras provincias del Tawantinsuyu (Alconini 2008; Coben 2006), reafirmando la idea de que la arquitectura es uno de los principales recursos usados por el Tawantinsuyu para la construcción social de un paisaje incaico y la aplicación de estrategias de dominación en sus provincias (Morris 1990, 1995; Niles 1992).

\section{La cuenca superior del río Aconcagua y el Complejo Arquitectónico Cerro Mercachas}

La cuenca superior del río Aconcagua se encuentra en la zona septentrional de Chile central y corresponde a un amplio valle compuesto por dos sectores: el área de San Felipe-Los Andes y el área de Putaendo, los cuales están separados por un importante cordón montañoso (Figura 1). Los estudios regionales han mostrado que en tiempos inmediatamente anteriores a la llegada del Inca (Período Intermedio Tardío 1000 circa 1450 d.C.), esta zona fue ocupada por comunidades campesinas con un bajo nivel de jerarquización y diferenciación social, un patrón de asentamiento disperso que muestra una escasa integración espacial de estas comunidades y una ausencia de grandes obras constructivas que indicasen un trabajo comunitario a gran escala (Pavlovic 2006).

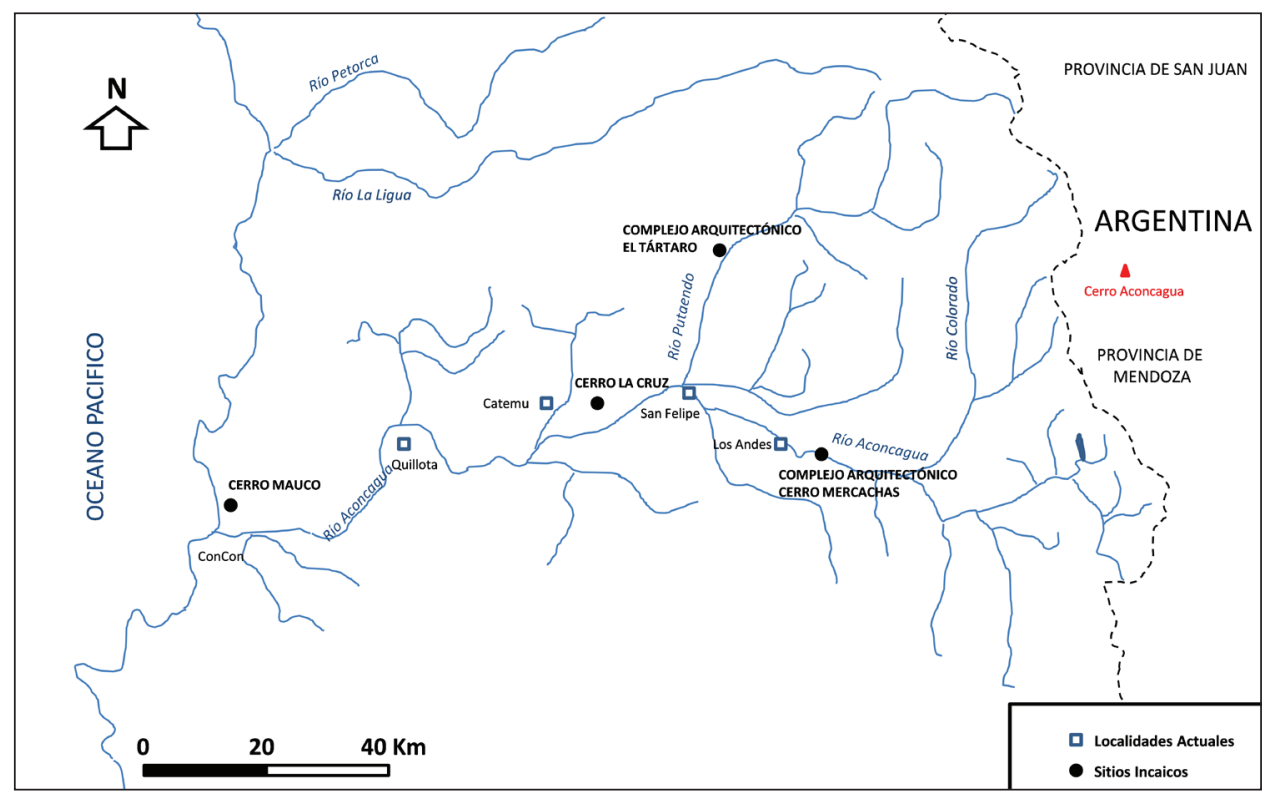

Figura 1: Mapa de la zona de estudio con indicación de los sitios y lugares nombrados en el texto. 
La ocupación asociada al período incaico en la zona es amplia y variada. La impronta estatal ha quedado registrada en el trazado de la red vial (Coros y Coros 1999; Sánchez 2001-02; Stehberg 1995), cementerios (Durán y Coros 1991; Madrid 1965), asentamientos habitacionales (Pavlovic et al. 2004; Sánchez 2004), el santuario de altura del cerro Aconcagua (Schobinger 2001), ocupaciones en cimas de cerro de mediana y baja altura (Pavlovic y Rosende 2010), y un conjunto de instalaciones arquitectónicas definidas como tambos, pucaras y centros administrativos (Garceau 2005; Sánchez 2001-02; Sanguinetti 1977; Stehberg 1995).

A pesar de este importante registro, los estudios orientados a definir las características específicas de los sitios y su vinculación con las estrategias regionales de dominación y ocupación incaica son escasos (Sanguinetti 1995; Stehberg 1976), predominando una interpretación apegada a los modelos administrativos burocráticos pensados desde el centro del Estado (p.e. Rodríguez et al. 2003; Silva 1985), los cuales se han desarrollado en modelos genéricos para entender este momento, pero sin una contraposición sistemática con la materialidad de la vida social expresada en el registro arqueológico.

Los modelos planteados para la ocupación inca en la zona, así como para Chile central (p.e. Llagostera 1977; Silva 1985; Stheberg 1995), sugieren que este área habría sido anexada por mitimaes provenientes de tierras más septentrionales, específicamente poblaciones diaguitas del Norte Semiárido de Chile (Sánchez 2004; Stehberg 1976), las cuales también se encargarían de anexar el centro oeste argentino (García 1997). Esta incorporación territorial habría tenido como fin acceder a recursos por integrar en el circuito de la economía política inca, específicamente el importante stock ganadero de las poblaciones locales y los recursos mineros de la zona (Stehberg 1976; Llagostera 1977; Silva 1985). Esto implicaba la inserción de una serie de instituciones administrativas e instalaciones defensivas para consolidar la anexión del territorio y subyugar posibles rebeliones de las poblaciones locales (Silva 1985; Stehberg 1976).

Esta dinámica generó una ocupación inca de la región caracterizada por su naturaleza dispersa, donde se observa una segregación espacial entre los asentamientos incaicos y los de las poblaciones locales (Sánchez 2004). Mientras los primeros se disponen mayormente sobre cerros, lo que ha llevado a interpretarlos básicamente como pucaras, los segundos se distribuyen por las terrazas fluviales disponibles en el fondo del valle. Es por ello que los sitios del Tawantinsuyu se constituirían en verdaderos enclaves espaciales, núcleos desde los que se establecería la incaización de las poblaciones locales (Sánchez 2004) y que se articularían por medio del trazado de la red vial.

El Complejo Arquitectónico Cerro Mercachas es parte del primer conjunto de sitios mencionados (Figura 1). Se ubica en las proximidades de la actual ciudad de Los Andes y se emplaza en la cumbre de una estribación montañosa de la cordillera andina, a una altitud de $1.600 \mathrm{msnm}$ y a $400-500 \mathrm{~m}$ de altura sobre las terrazas fluviales del valle (Figura 2). Tiene como particularidad que su cumbre es una planicie que se extiende por más de $300 \mathrm{~m}$ de largo, por lo que el macizo también se conoce con el nombre de La Mesa. 


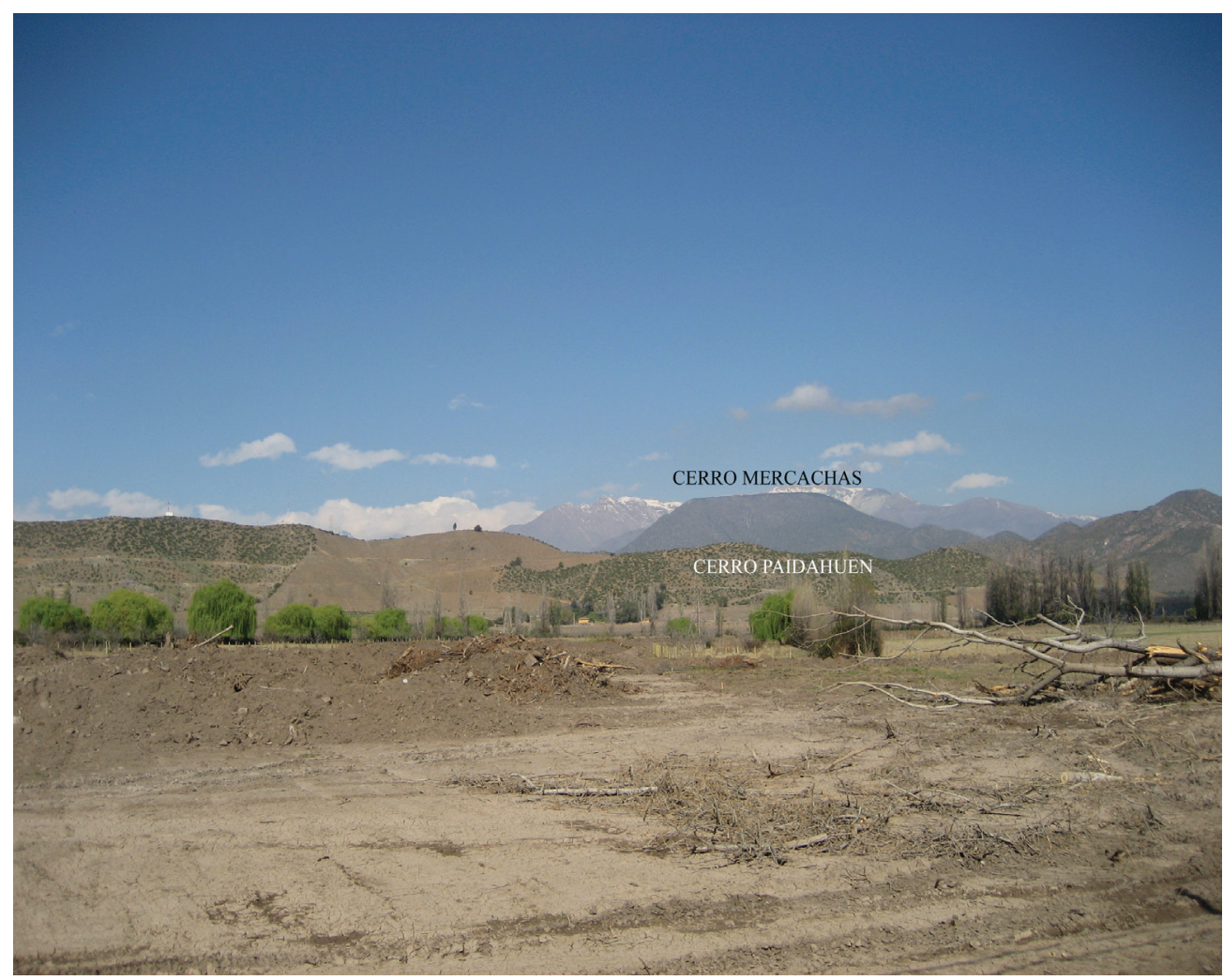

Figura 2: Vista del Cerro Mercachas y Cerro Paidahuen.

La altura y dimensiones del cerro, así como su particular cumbre plana, hacen de Cerro Mercachas un hito extremadamente significativo dentro del paisaje local, destacando tanto por su morfología como por su alta visibilidad en el entorno. A la inversa, desde su cumbre se tiene una visión privilegiada de toda la cuenca superior del Aconcagua, y una vista directa del santuario del Cerro Aconcagua, principal waka incaica de la región (Schobinger 2001) y que es visible desde pocos lugares de la zona.

El complejo está delimitado por un muro perimetral que encierra un área cercana a los $120.764 \mathrm{~m}^{2}$ y en cuyo interior se ha reconocido un total de 43 estructuras (Figura 3). Si bien algunos autores plantean la posible existencia de recintos de momentos preincaicos (Rosen et al. 2010), la totalidad del contexto arquitectónico del sitio se asocia al período Tardío o Inca porque: 1) todos los recintos son coherentes con los patrones constructivos y formales de la arquitectura inca en la zona, 2) la totalidad del contexto de cultura material mueble se asigna a tal momento y 3) se tienen dos dataciones absolutas por termoluminiscencia, de $1475 \pm 50$ d.C. (UCTL1406) y $1390 \pm 60$ d.C. (UCTL-1405) (Sánchez 2004), coherentes con tal filiación. 

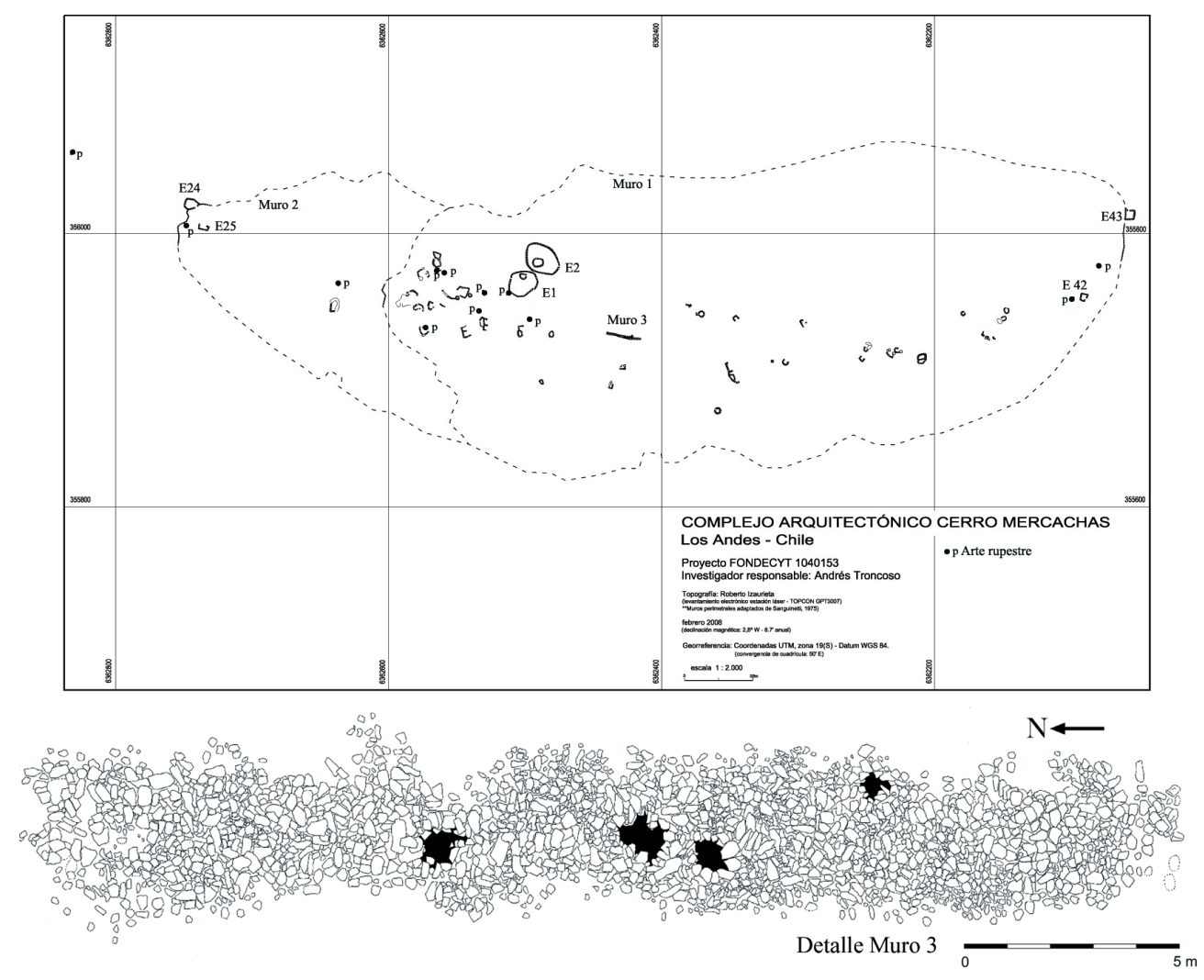

Figura 3: Levantamiento topográfico del sitio Complejo Arquitectónico Cerro Mercachas y detalle del Muro 3.

Junto a estas estructuras se reconocen 13 bloques de arte rupestre que se distribuyen tanto en el área encerrada por el muro perimetral, como formando parte de éste y de muros de recintos.

La disposición de esta instalación en la cumbre de un cerro y la presencia de un muro perimetral llevó a los primeros investigadores del sitio a definirlo como una fortaleza o pucara (Sanguinetti 1975), en consonancia con los modelos de interpretación del registro arquitectónico incaico tradicionales. Sin embargo, y como mencionaron varios autores posteriormente, la ausencia de recursos hídricos en la cercanía del sitio, así como el aislamiento espacial en relación con el resto de la cuenca superior del río Aconcagua y con las zonas de cultivo, hacían poco factible pensar este sitio como un lugar de control y atrincheramiento en caso de conflicto (Sánchez 2004; Stehberg y Sotomayor 1999).

Más recientemente, Stehberg y Sotomayor (1999) propusieron interpretar el sitio como una waka-fortaleza, es decir, como una instalación que mantiene un patrón constructivo de tipo fortaleza, pero que funcionaría como un espacio sagrado. Sus fundamentos descansan en que el análisis de documentos coloniales sugiere que 
este macizo se ubicaría dentro de un lugar especialmente privilegiado en el interior de una unidad política territorial preincaica (cavi). Esta hipótesis fue luego ampliada por Sánchez (2001-02, 2004), definiendo el sitio como una waka instalada por el Tawantinsuyu con el fin de legitimar su ocupación del territorio dentro de un contexto de dominación centrado en la eficacia de las conductas ceremoniales, antes que en una explotación económica del territorio.

No obstante estas nuevas propuestas sobre el sitio que enfatizan la relevancia de la instalación dentro del contexto regional, vemos que ninguna de ellas descansa en un análisis de los conjuntos espaciales y materiales del complejo, lo que no sólo disminuye de manera significativa el potencial de las hipótesis esbozadas por los autores, sino que también impide una comprensión sistemática del sitio, de la dinámica de las prácticas sociales efectuadas en el lugar y del modo en que éstas se integran en una realidad de carácter más regional sobre la que se establece la ocupación inca del territorio.

Metodológicamente, los trabajos realizados en CACM se basaron en una estrategia de investigación que implicó tres tipos de labores diferentes: 1) excavaciones en área en diferentes recintos con el fin de recuperar cultura material mueble que indicase el tipo de prácticas sociales efectuadas en el lugar, 2) registro y relevamiento de la arquitectura según las propuestas de Letelier (2009), orientadas a comprender la organización espacial interna del sitio y posible funcionalidad de los recintos y 3) registro y relevamiento del arte rupestre según las propuestas de Troncoso (2008), para definir la asignación estilística de los diseños y evaluar su dinámica espacial en el interior del sitio. Los resultados de tal labor se presentan en el siguiente apartado y son la base para discutir la funcionalidad y papel del CACM en la ocupación incaica de la zona.

\section{Contextos materiales y prácticas sociales}

Tres son los conjuntos de evidencias materiales que permitirán discutir la dinámica de la ocupación en el sitio: arquitectura, arte rupestre y cultura material mueble recuperada a partir de las excavaciones estratigráficas efectuadas.

\subsection{Arquitectura}

La arquitectura del sitio se compone de 43 recintos y tres muros dispuestos en diferentes sectores (Figura 3). Las primeras se caracterizan por corresponder a construcciones de pequeña escala basadas únicamente en la disposición de rocas para la creación de muros dobles de muy baja altura (actualmente no sobrepasan una hilada de piedra y los $10 \mathrm{~cm}$.), sin utilización de argamasas que las aglutinen ni basamentos que se profundicen en el suelo (Figura $4 \mathrm{a}$ y b). Tampoco se observan altas cantidades de rocas asociadas a derrumbes. La mayor parte de estas construcciones son de tipo abierto, en forma de $\mathrm{U}$ y de reducidas dimensiones (áreas de $4 \mathrm{a} 10 \mathrm{~m}^{2}$ ). Esto sugiere que nos encontraríamos ante estructuras cuya función no sería habitacional, por 
cuanto su reducido espacio interior permite únicamente la disposición de una o dos personas, sin que exista un espacio sobrante de movilidad para la realización de actividades domésticas o productivas. A su vez, la ausencia de basamentos en los muros supone una debilidad estructural que imposibilita el sostenimiento de algún tipo de estructura aérea importante.
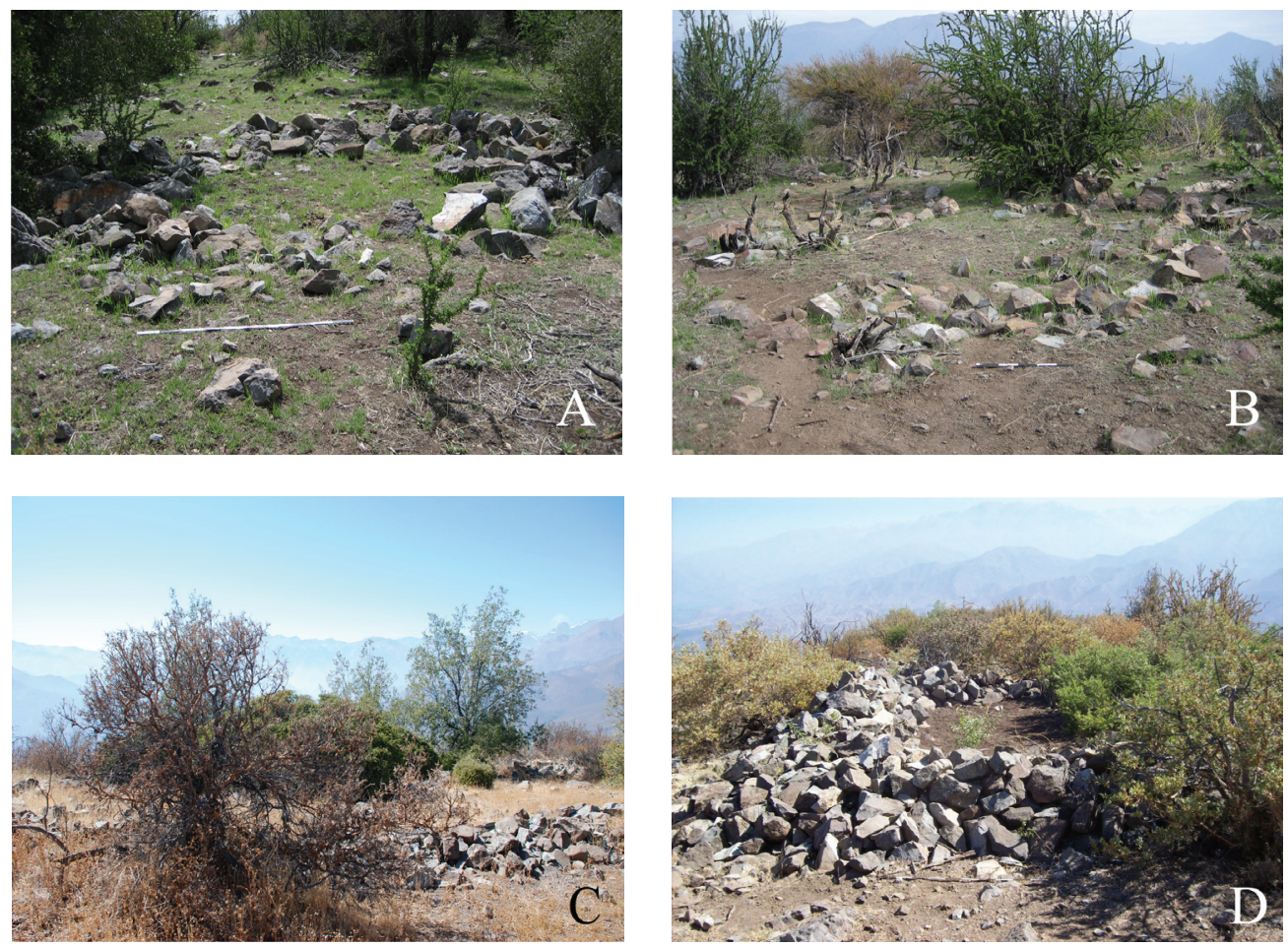

Figura 4: Estructuras arquitectónicas del Complejo Arquitectónico Cerro Mercachas: a) recinto 17, b) recinto 19, c) recinto 2, d) recinto 25 .

El carácter poco formalizado de estos recintos se refrenda también en que muchos de ellos aprovechan grandes rocas naturales para la constitución de los muros y delimitación de los espacios. En algunos casos, estos mismos muros encierran grandes bloques rocosos. Ambos aspectos han sido reconocidos para otros conjuntos arquitectónicos del Tawantinsuyu (p.e. Gasparini y Margolies 1977; Niles 1992).

Existen sólo seis estructuras que difieren de este patrón, constituyéndose en formas más estandarizadas, con una tendencia hacia la clásica morfología arquitectónica cuadrangular incaica (Hyslop 1990; Kendall 1976), y con una inversión de trabajo mayor al resto del conjunto, reflejada en la altura y extensión de sus muros (Figura $3,4 \mathrm{c}$ y d). De ellas, dos son las construcciones centrales del sitio, las estructuras 1 y 2 (E1 y E2, respectivamente), localizadas en el centro del complejo arquitectónico. Ambas son grandes recintos que habrían permitido una importante reunión de personas en su interior (247,39 $\mathrm{m}^{2}$ y 165,04 $\mathrm{m}^{2}$ de área interior respectivamente). A éstas 
les siguen la estructura 43 (E43, área interior de 29,68 $\mathrm{m}^{2}$ ), ubicada en el extremo sur del sitio, y la estructura 24 (E24, área interior de $50,7 \mathrm{~m}^{2}$ ), localizada en su extremo norte (Figura 3). Los dos últimos recintos se edifican aprovechando el muro perimetral del sitio y se disponen fuera de éste. Finalmente, se encuentran las estructuras 42 (E42, área interior de $14,78 \mathrm{~m}^{2}$ ) ubicada en el extremo Sur del sitio y aledaña a E43; y la estructura 25 (E25, área interior de $18 \mathrm{~m}^{2}$ ) ubicada en el extremo Norte y aledaña a E24 (Letelier 2009)

Las restantes estructuras no responden de forma tan clara al patrón formal de la arquitectura definida para el Tawantinsuyu, tal como lo evidencia la presencia de formas circulares, lineales y elipsoidales entre otras (Letelier 2009). Sin embargo, su técnica constructiva, similar a la de los otros recintos del sitio, y la ausencia de este tipo de registro en momentos previos de la historia prehispánica local avalan su adscripción al período Inca.

Junto a estas estructuras se reconocen tres muros dentro del sitio, dos de los cuales son parte del muro perimetral (Figura 3). El primero (muro 1) es un extenso alineamiento de piedras que cierra el sitio completamente por sus sectores sur, este y oeste y establece un primer cerco en el área centro-norte. El segundo (muro 2) nace desde las esquinas NE y NO del muro 1 y se proyecta más hacia el Norte, delimitando el sitio por tal lado y creando una división de dos espacios al interior del CACM. El muro 3 es una estructura lineal cercana a los $26 \mathrm{~m}$ de largo y $1,8 \mathrm{~m}$ promedio de ancho, ubicada en el sector central del sitio y sin asociación directa con ningún recinto. Dos son las particularidades de esta estructura; primero, presenta una clara alineación hacia el Norte (su eje se encuentra desviado $3^{\circ}$ ), y segundo, tiene en su interior cuatro espacios circulares sin rocas que han sido construidos intencionalmente (Figura 3). Estos agujeros se encuentran a lo largo del muro, ubicándose tres de ellos en el mismo eje del muro, mientras que el cuarto está desplazado levemente hacia el Este en un quiebre dentro de la lógica de esta construcción.

No obstante la gran cantidad de estructuras arquitectónicas, al evaluar la relación entre el número de espacios construidos y el área delimitada por el muro perimetral, encontramos que un sector muy pequeño del sitio se encuentra estructurado a partir de los recintos arquitectónicos (menos de 1\% que corresponden a $912 \mathrm{~m}^{2}$ de $120.764 \mathrm{~m}^{2}$ ).

Esta conformación espacial de la arquitectura genera dos patrones bastantes interesantes por discutir. Primero, una clara segregación del espacio en dos sectores, uno de mayor tamaño y que es donde se concentra el grueso de los recintos, y otra de menor extensión espacial donde sólo se ubican unas pocas estructuras arquitectónicas y que coincide con lo que es el extremo norte del sitio. Formalmente, ambos espacios se encuentran separados por el muro 1.

Segundo, una organización espacial de tipo lineal, privilegiando un eje de tipo SurNorte. La observación de la distribución de los recintos muestra cómo se establecen ordenadamente según esta línea, sin que sea posible reconocer otros ejes de fuerza en esta ordenación. En este recorrido claramente es posible reconocer tres puntos como relevantes: 1) la estructura 43, ubicada al ingreso del sitio y que es uno de los dos recintos que se ubica por fuera del muro perimetral, y que coincide con ser una de las estructuras de mayor tamaño en el sitio, al igual que el recinto 44 que está próximo a éste y que tiene similares características; 2) las estructuras 1 y 2 , emplazadas en el 
sector central, que son las de mayor dimensión y en torno a las cuales, además, se concentran un conjunto de otras construcciones y el muro 3; 3) las estructuras 24 y 25 , que se disponen al finalizar todo el recorrido, las que nuevamente alcanzan tamaños mayores al resto de los recintos y que, en el caso de la primera, vuelve a ocurrir que se encuentra por fuera del muro perimetral, aunque con un acceso directo desde el interior.

Esta conformación espacial de la arquitectura reafirma esta idea de direccionalidad del movimiento en el interior del sitio, marcando tres puntos relevantes que pueden ser pensados como pausas: el ingreso, el sector medio y el final. Es significativo que en el sector medio del sitio es donde se disponen las dos estructuras de mayor tamaño (que posibilitan una mayor agregación de gente), donde se han recuperado mayor cantidad de restos artefactuales, y que tales recintos son los únicos que muestran -en la lógica de un análisis gamma (véase Hillier y Hanson 1984: cap. 4)- dos conexiones topológicas: una para ingresar a la estructura y otra para acceder a un subrecinto interior. Es en este punto también donde se concentra un elevado número de recintos de menor tamaño y el muro 3 , de función indeterminada.

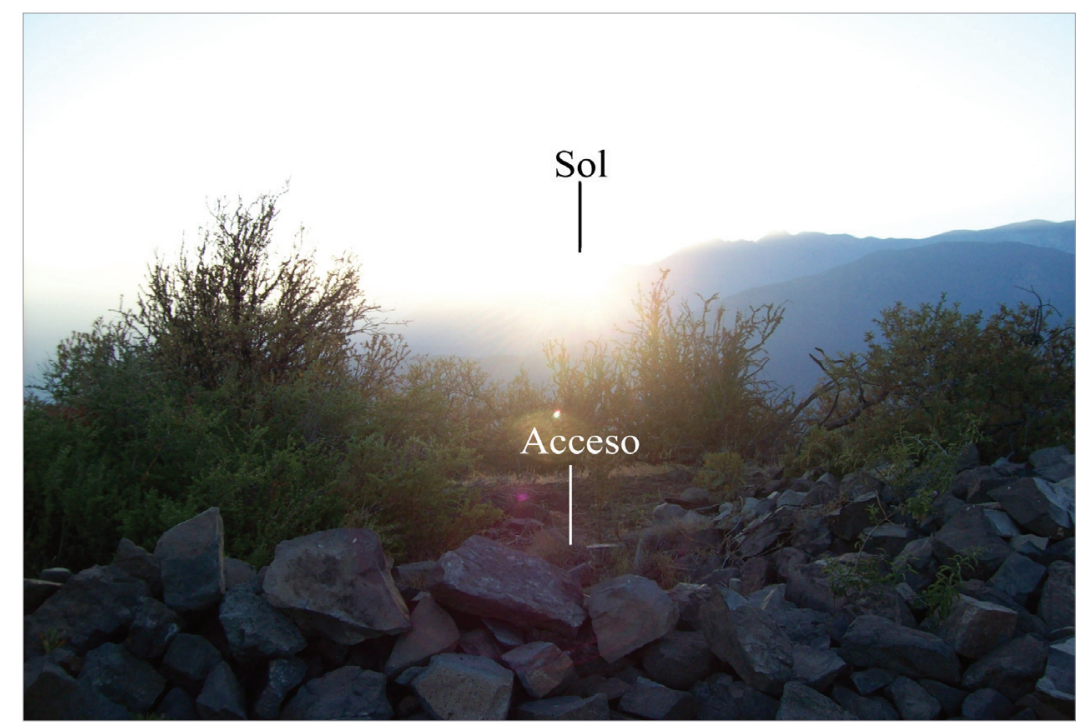

Figura 5: Amanecer del solsticio de diciembre desde el acceso del recinto 25.

Finalmente, se procedió a realizar un análisis de la orientación de los vanos de estas estructuras. Observando desde el interior de ellas, se reconoció que los vanos de los dos recintos finales (E24 y E25) tenían orientaciones significativas (Figura 5). E25 orienta su acceso hacia el amanecer del solsticio de diciembre (verano en el Cono Sur), mientras que E24 se orienta hacia el Cerro Aconcagua, lugar por el que aparecen también las Pléyades (Cuadro 1). Para la latitud de cerro Mercachas y en la época de uso de las estructuras, la primera aparición de las Pléyades, su orto helíaco, ocurriría hacia comienzos de junio, apenas unos pocos días antes del solsticio 
de junio. Esto sugiere una interesante asociación entre la principal waka incaica de la región (cerro Aconcagua) y la aparición de las Pléyades, que según autores como Bauer y Dearborn (2003) serían las principales estrellas sujetas a observación en el Tawantinsuyu, dada su asociación con la producción de maíz, por lo que «su aparición y desaparición fueron seguidas con gran interés» (Bauer y Dearborn 2003: 168), así como la cercanía visual con la salida del sol en el solsticio de junio.

Se exploró la posibilidad de orientaciones astronómicas también para las estructuras 1 y 2 , pero el mal estado de los recintos interiores no permitió reconocer de manera clara un rumbo exacto, aunque dentro del subrecinto de la estructura 1 se observó un vacío que se orientaba hacia la salida del sol en el solsticio de junio (Cuadro 1). Para la estructura 43 no se reconoció alineación alguna.

El carácter poco formalizado del resto de los recintos y el gran arco que abarcaban sus aberturas no llevó a buscar alineaciones astronómicas, pues estas serían de escasa confiabilidad.

Cuadro 1: Registro de orientaciones con valor astronómico en el Complejo Arquitectónico Cerro Mercachas

\begin{tabular}{lcccl}
\hline \multicolumn{1}{c}{ Estructura } & Azimut $\left({ }^{\circ}\right)$ & Altura del horizonte $\left({ }^{\circ}\right)$ & Declinación $\left(^{(}\right)$ & \multicolumn{1}{c}{ Objeto } \\
\hline Estructura 1 & 59 & 3 & 23 & Solsticio de junio \\
Estructura 24 & 59,64 & 3,4 & 23,19 & $\begin{array}{l}\text { Solsticio de junio } \\
\text { Pléyades/Aconcagua }\end{array}$ \\
Estructura 25 & 115 & 4 & -23 & $\begin{array}{l}\text { Solsticio de diciembre } \\
\text { Petroglifo 1 }\end{array}$ \\
Paidahuen & 115 & 4 & -23 & Solsticio de diciembre \\
\hline
\end{tabular}

\subsection{Arte rupestre}

Alternando espacio con los recintos, y en un caso formando parte del muro de una de ellas (E2) y en otro del muro 1, se encuentran trece bloques con grabados de petroglifos, todos los cuales corresponden a diseños no figurativos, a excepción del bloque 1 (Urzúa 2008) (Figura 3).

En términos generales, los grabados se dividen en dos conjuntos. Uno compuesto básicamente por piquetados y raspados lineales que no conforman diseño identificable alguno $(\mathrm{N}=4)$ (Figura 6a), y otro conformado por la aplicación de círculos, cuadrados y óvalos para la constitución de diseños no figurativos. Dentro de estos últimos destaca la presencia de óvalos y cuadrados con trazos oblicuos internos que reproducen el diseño incaico de la clepsidra (Figura 6b). La aplicación de los criterios que definen los estilos de arte rupestre para la cuenca superior del río Aconcagua (Troncoso 2005, 2008) permite adscribir la totalidad de los bloques al período Tardío, aunque en uno de ellos se reconoce la presencia de grabados del momento inmediatamente previo (período Intermedio Tardío), los cuales están en superposición bajo diseños de tiempos inca. Al respecto, si bien la posibilidad de un arte rupestre incaico como tal es un tema de amplia discusión en los Andes del Sur (p.e. Berenguer y Cabello 2005; Gallardo y Vilches 2001; Hernández Llosas 2006; Sepúlveda 2004), los trabajos en esta zona han permitido reconocer producciones 
rupestres que remiten a los patrones de construcción de los lenguajes visuales incaicos, sin que ello implique necesariamente que su manufactura fuera realizada por personas de origen cuzqueño (Troncoso 2005, 2008).

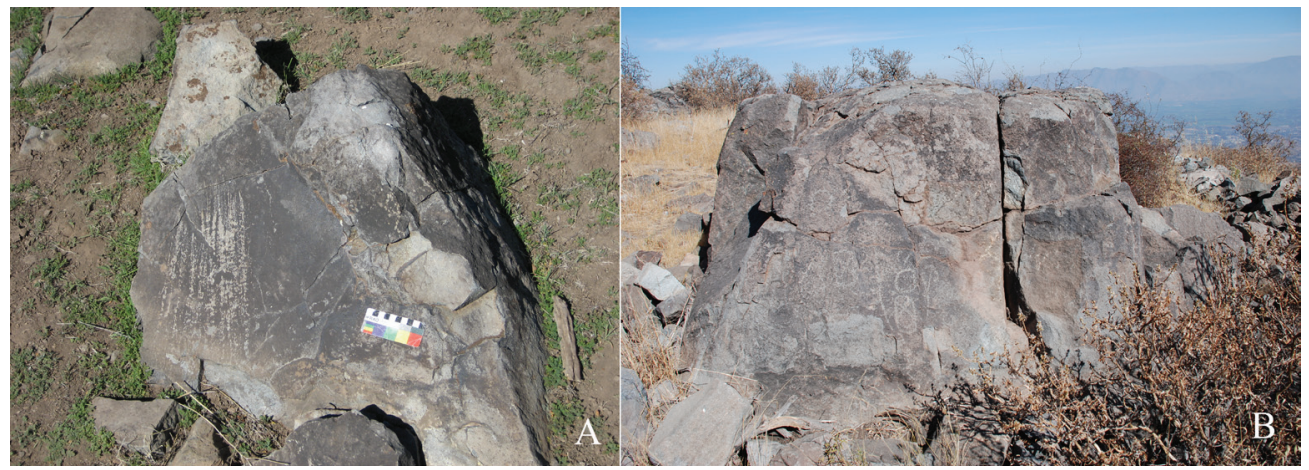

Figura 6: Grabados del Complejo Arquitectónico Cerro Mercachas: a) bloque 8 con raspados, b) bloque 1 con diseño de clepsidra.

La distribución de todos los bloques grabados reproduce la organización espacial lineal, con una clara concentración en el sector medio y final del sitio, tal como ocurre también con la arquitectura. Es así que en el ingreso del sitio se disponen dos bloques con petroglifos próximos a la E43, y posteriormente se disponen otros 7 bloques en el sector central y en torno a las E1 y E2; de hecho, uno de los bloques con grabados es parte del muro de E2. En ellos se combinan simplemente raspados con otros diseños más complejos de tipo no figurativo, tales como las clepsidras. En el extremo norte del sitio se ubican otros dos bloques con petroglifos, uno de los cuales aprovecha una gran roca que se utiliza como parte del muro perimetral 2. Finalmente, un bloque aislado se ubica aún más al norte, ya traspasando el muro perimetral y en un piso más bajo que el complejo arquitectónico. Se reitera por tanto, con el arte rupestre, el sistema de linealidad e intensidad espacial reconocido en la arquitectura.

Aun más, el bloque 1, ubicado en el extremo norte y junto al muro perimetral, es el único soporte que tiene una representación antropomorfa, diferenciándose completamente del restante conjunto rupestre (Figura 6b). Este personaje destaca también porque su cuerpo reproduce el diseño de la clepsidra, atributo que en otras zonas como el Norte Grande de Chile ha sido interpretado como indicador de un tipo de vestimenta incaica (Montt 2005). Este mismo bloque tiene su panel con grabados orientados hacia el punto donde nace el sol en el amanecer del solsticio de diciembre.

\subsection{Cultura material mueble}

Se realizaron excavaciones sistemáticas en los diferentes sectores del sitio, las cuales abarcaron un total de $29 \mathrm{~m}^{2}$, comprendiendo tanto espacios interiores de recintos como áreas aledañas a petroglifos (Cuadro 2). El resultado fue una baja recuperación de 
cultura material, compuesta únicamente por fragmentos cerámicos y artefactos líticos. Estos materiales se concentraron en la estructura 2 con un buen número de recintos sin ningún hallazgo (Cuadros 2 y 3 ).

La totalidad de la cerámica recuperada se asocia al período Incaico. Hay una alta frecuencia de fragmentos engobados/decorados $(56,8 \%)$ por encima de los monocromos $(30,7 \%)$ (Cuadro 3). Los primeros son restos de vasijas de formas restringidas de gran tamaño, debido a que sus superficies interiores carecen de pulido y/o engobe, y sus cuerpos tienen una escasa curvatura; posiblemente corresponden a restos de aríbalos (Figura 7). Debido al grado de fragmentación no fue posible reconocer los tipos de diseños de estas piezas. Estos resultados son similares a los obtenidos previamente por González (2003) y Sanguinetti (1975), quienes también recuperaron restos de platos planos de las estructuras principales, los cuales, junto con los aríbalos, son parte de la vajilla ritual básica incaica (Bray 2003).

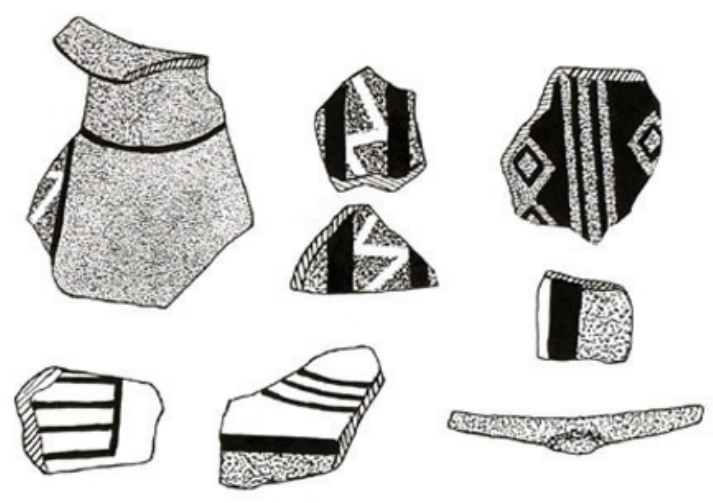

Figura 7: Fragmentos cerámicos recuperados en las excavaciones del sitio.

El conjunto lítico, muy escaso, se define por la presencia mayoritaria de derivados de núcleo sin modificaciones $(92,8 \%)$ y dos instrumentos: una preforma de punta de proyectil triangular y un núcleo.

Cuadro 2: Áreas excavadas y materiales recuperados

\begin{tabular}{lrlll}
\hline Unidad & Área excavada & \multicolumn{1}{c}{$\begin{array}{c}\text { Profundidad de } \\
\text { excavación }\end{array}$} & \multicolumn{2}{c}{ Material cultural recuperado } \\
& & & Cerámica & Lítica \\
\hline Estructura 1 & $2 \mathrm{~m}^{2}$ & $15 \mathrm{~cm}$ & 2 & 1 \\
Estructura 2 & $6 \mathrm{~m}^{2}$ & $20 \mathrm{~cm}$ & 240 & 11 \\
Estructura 13 & $2 \mathrm{~m}^{2}$ & $15 \mathrm{~cm}$ & 0 & 1 \\
Estructura 24 & $4 \mathrm{~m}^{2}$ & $15 \mathrm{~cm}$ & 1 & 0 \\
Estructura 25 & $8 \mathrm{~m}^{2}$ & $15 \mathrm{~cm}$ & 109 & 14 \\
Muro 3 & $3 \mathrm{~m}^{2}$ & $10 \mathrm{~cm}$ & 0 & 0 \\
Petroglifo 1 & $2 \mathrm{~m}^{2}$ & $15 \mathrm{~cm}$ & 0 & 0 \\
Petroglifo 4 & $2 \mathrm{~m}^{2}$ & $20 \mathrm{~cm}$ & 0 & 0 \\
Total & $\mathbf{2 9} \mathbf{m}^{2}$ & & $\mathbf{3 5 2}$ & $\mathbf{2 7}$ \\
\hline
\end{tabular}


Cuadro 3: Características de la alfarería recuperada en las excavaciones en el sitio

\begin{tabular}{lrrrr}
\hline Unidad & $\begin{array}{c}\text { Cerámica } \\
\text { monocroma }\end{array}$ & $\begin{array}{c}\text { Fragmentos de } \\
\text { cerámica engobada } \\
\text { / decorada }\end{array}$ & $\begin{array}{c}\text { Fragmentos de } \\
\text { cerámica erosiona- } \\
\text { da / pequeña }\end{array}$ & TOTAL \\
\hline Estructura 1 & \multicolumn{1}{c}{ 1 } & 145 & 0 & $\mathbf{2}$ \\
Estructura 2 & 84 & 0 & 11 & $\mathbf{2 4 0}$ \\
Estructura 13 & 0 & 1 & 0 & $\mathbf{0}$ \\
Estructura 24 & 0 & 54 & 0 & $\mathbf{1}$ \\
Estructura 25 & 22 & 0 & 33 & $\mathbf{1 0 9}$ \\
Muro 3 & 0 & 0 & 0 & $\mathbf{0}$ \\
Petroglifo 1 & 0 & 0 & 0 & $\mathbf{0}$ \\
Petroglifo 4 & 0 & $\mathbf{2 0 0}$ & $\mathbf{4 4}$ & $\mathbf{3 5 2}$ \\
Total & $\mathbf{1 0 8}$ & &
\end{tabular}

\section{Dinámica espacial y arquitectónica del Complejo Arquitectónico Cerro Mercachas}

Los resultados de la investigación en el CACM muestran la presencia de un registro material amplio que combina tanto elementos inmuebles -arquitectura y arte rupestre-como elementos muebles. Sin embargo, estos últimos son notoriamente escasos, remitiéndose únicamente a unos pocos fragmentos cerámicos y artefactos líticos concentrados en un par de recintos arquitectónicos. Pensamos que estos resultados son un reflejo del comportamiento general del sitio, pues las intervenciones estratigráficas previas efectuadas, y no publicadas, han llegado a similares resultados (González 2003; Stehberg com. pers.).

La arquitectura y el arte rupestre son, en contraposición, elementos materiales más visibles y ubicuos en el sitio. Mientras la primera presenta una gran heterogeneidad, respetando sólo un par de recintos los patrones formales incaicos, todos ellos son construidos durante este tiempo, tal como lo sugiere la similitud de las rocas, su disposición en los muros y el contexto general del sitio. Esta heterogeneidad formal y poca cercanía con los patrones arquitectónicos más clásicos del Tawantinsuyu es un rasgo compartido con todos los otros sitios incaicos en altura presentes en el valle de Aconcagua (Complejo Arquitectónico El Tártaro, Cerro La Cruz y Cerro Mauco). $\mathrm{El}$ arte rupestre, por su lado, si bien es un registro material poco conocido para tiempos incaicos dentro del Tawantinsuyu, ha ido ganando cada vez más visibilidad en diferentes sectores del Collasuyu, reconociéndose su presencia en el interior de otros sitios incas, tales como el pucara de Turi en el Norte Grande de Chile (Gallardo y Vilches 2001), o el mismo Complejo Arquitectónico El Tártaro en Aconcagua (Troncoso 2008); por lo que su registro en el CACM, si bien es novedoso, no es exclusivo.

Las características del registro arquitectónico y de la cultura material mueble sugieren, en conjunto, un uso esporádico del sitio y en ningún caso de tipo residencial. El escaso registro de bienes muebles y la poca variedad de actividades representadas en el lugar no son coherentes con las expectativas propias de un sitio de tipo habitacional o de carácter administrativo. 
Este uso esporádico del asentamiento se articularía a partir de una dinámica centrada en la organización lineal del espacio y el movimiento de los sujetos en su interior siguiendo este principio espacial. Tanto la arquitectura como el arte rupestre se disponen según este eje, de dirección Sur-Norte, y donde se dan tres puntos significativos: el ingreso, el centro y el final. En la arquitectura este sistema de recorrido se define por la presencia de recintos más amplios y que se ajustan de manera más clara a lo que es el patrón constructivo incaico. En el arte rupestre viene dado por lo que es la presencia de bloques con grabados.

De esta manera, el ingreso al sitio está marcado por la E43, junto a la que se registran dos bloques con grabados, en particular círculos. Tras este ingreso se traspasan varias estructuras arquitectónicas menores, que por su tamaño no permiten el ingreso de más de una persona, para acceder al sector central. En este punto vuelven a aparecer dos recintos, los dos de mayor tamaño del sitio (E1 y E2) y que son los únicos en todo el sitio que presentan subestructuras interiores. A ellas se suman un conjunto de otros recintos de pequeña magnitud, nueve bloques de arte rupestre y el muro 3. Es este uno de los espacios donde se concentra el registro de cultura material mueble, desplegándose prácticas que implican el uso de aríbalos y, por ende, el consumo de chicha, bebida alcohólica central en la ritualidad y economía política incaica (Bray 2003; Dillehay 2002). Finalmente, traspasado este punto, se recorre otro espacio de pequeños recintos hasta llegar al último lugar del CACM, donde nuevamente nos encontramos con dos recintos de grandes tamaños con una tendencia a formas arquitectónicas más incaicas, uno de los cuales también muestra una alta concentración de cultura material mueble (E24), y un gran bloque de arte rupestre donde destaca un personaje antropomorfo con cuerpo de clepsidra.

Esta organización espacial del registro inmueble conformaría, por tanto, un sistema arquitectónico articulado centrado en el movimiento a través del sitio por parte de los sujetos, estableciéndose posiblemente pausas en cada uno de ellos. Las diferencias en los residuos materiales de estos espacios expresan la divergencia de las prácticas acaecidas en cada uno de ellos. En ese contexto, el sector central pasaría a ser el espacio donde posiblemente se concentra la acción social, tanto por el registro de los recintos más grandes y complejos del sitio, como porque en su entorno se concentran bloques con grabados y en su interior encontramos evidencias de consumo de chicha.

Esta organización reproduce en el espacio interno del CACM un principio que ha sido reconocido en la dinámica ritual incaica en otros espacios: la organización en tres o tripartición. Este principio no es sólo un recurso básico en la organización espacial, social y administrativa del Tawantinsuyu (Zuidema 1991), sino que ha sido observado en otros sitios rituales incaicos. En el caso de la Isla del Sol, en Bolivia, Bauer y Stanish (2003) identifican un sistema de movilidad como el acá reconocido que incluye el traspaso de tres grandes puertas que marcan distintas etapas en un peregrinaje; Topic (2008; Curatola 2008) reconoce también una organización de tres sectores en el santuario de Catequil, en Perú; en el mismo valle de Aconcagua, un similar sistema basado en un recorrido según un eje vertical que cruza tres pisos de altura diferentes se ha identificado en el sitio Cerro La Cruz (Troncoso et al. 2011). Esta organización no sólo materializa este principio en el CACM, sino que también, como 
lo indica Curatola (2008) para otros casos, lo transforma en un axis mundi donde se combinan y articulan los tres pisos que definen la organización cosmológica incaica.

La organización espacial, por tanto, es coherente con lo que podemos denominar un movimiento ritual. Como bien lo han indicado diferentes autores (Bell 1997; Coleman y Elsner 1994; Leach 1993; Parkin 2002), uno de los elementos esenciales en la producción del ritual es la sintaxis del movimiento y su direccionalidad, pues ella no sólo se articula con la actuación y la experiencia de estar-en-el-espacio, sino también con los contenidos y normas que intenta comunicar esta actividad a los participantes. A través de estos recorridos, las pausas establecen límites imaginarios que estratifican el espacio construido y los contenidos, creando integraciones/segregaciones entre los conjuntos de sujetos participantes y distintas escenificaciones con valor semántico.

En la misma línea, tanto en la cosmología andina (Cereceda 1988) como en la teoría del ritual de Leach (1993), el centro es el espacio más significativo, por cuanto en él se establece la mediación entre los diferentes segmentos que constituyen el mundo. En CACM esto se refrenda no sólo en que es en el centro donde se encuentra la mayor cantidad de recintos, sino que en él están los más grandes y complejos (E1 y E2) y el muro 3, de función indeterminada. Esta conformación de E1 y E2 como centro marca también una separación entre las características de los extremos sur y norte del sitio, que funcionan como secciones opuestas. Por una parte, la mitad sur se define como un espacio abierto sin segregaciones internas, mientras que la mitad Norte se encuentra segmentada por el muro 1. Por otra parte, cada uno de los extremos de ambos espacios presenta similar número de bloques con arte rupestre $(\mathrm{N}=2)$, pero, mientras los de la mitad sur no presentan clepsidras, los de la zona norte sí. Ambos extremos también presentan igual número de estructuras (N=2; E43 y E42 para el Sur, E25 y E24 para el Norte), el cual se corresponde con las otras cuatro estructuras cuyas formas remiten más cercanamente a los patrones incaicos. Pero ambos conjuntos de recintos se oponen entre si, pues los de la mitad sur no presentan alineaciones significativas, mientras que los de la mitad norte sí (solsticio de diciembre y cerro Aconcagua).

Esta conformación espacial del CACM no sólo sería solidaria con su interpretación como sitio ceremonial orientado al movimiento ritual, como lo habían adelantado otros autores (Sánchez 2001-02, 2010; Stheberg y Sotomayor 1999), sino que en su organización espacial se combinarían dos principios básicos de la cosmología incaica: la tripartición y la oposición de unidades. El movimiento de los sujetos en el espacio, por tanto, se organizaría en un espacio construido a partir de los principios de la cosmología incaica, permeando las diferentes partes de cada una de esas segmentaciones a partir del recorrido, reafirmando su idea de axis mundi.

El carácter esporádico de la ocupación del sitio y la presencia de alineaciones astronómicas en los recintos ubicados en el extremo sur y en el petroglifo adyacente a ellos, permiten sugerir que la ritualidad del CACM se relacionaría, al menos, con dos fechas centrales del calendario incaico metropolitano: el capac Raymi y la aparición de las Pléyades próximas al Inti Raymi (Ziółkowski y Sadowski 1989).

En este contexto, la escasa superficie construida dentro del área delimitada por el muro perimetral de CACM es coherente con esta dinámica, más orientada a un uso por medio del desplazamiento de los sujetos en el espacio, antes que ser ocupado como un espacio defensivo (que debería presentar instalaciones que dificultasen el movimiento 
interno) o como un espacio con funciones administrativas (que debería tener instalaciones con mayor estandarización funcional y un uso más eficiente del espacio). El escaso registro de cultura material mueble, interpretado como una medida del tipo, cantidad y variedad de prácticas efectuadas en el lugar; sumado a las dificultades de acceso al sitio producto de su gran altura, y el que las estructuras que permiten la agregación de personas no son de tamaños excesivamente grandes, hacen pensar en la posibilidad de que estas festividades rituales no congregasen a grandes cantidades de personas.

Este último aspecto es coherente con la propuesta de Coben (2008) de entender estas grandes construcciones estatales como sitios en los que se plasma el calendario ritual incaico, con espectáculos y ceremonias restringidas en términos de público, orientadas más bien a una audiencia estatal que a las comunidades locales. Esto es coherente, a su vez, con el tipo de cerámica identificada en el sitio, donde no ingresan vasijas de morfología y decoración propias de las comunidades locales, sino que sólo se reconocen piezas inca local, es decir, vasijas de forma cuzqueña, pero de manufactura local. Las excavaciones realizadas en otros sitios del valle muestran que estas piezas circulan únicamente en estos contextos asociados con arquitectura incaica, estando ausentes en los asentamientos habitacionales emplazados en los fondos de valle, donde más bien predomina la cerámica tradicional de las poblaciones locales (Pavlovic 2011).

Sin embargo, en este espacio se materializan también prácticas sociales propias de las comunidades locales. Nos referimos a la producción de arte rupestre, práctica material que se desarrolla desde el período Intermedio Tardío en la región y que mantiene sus lineamientos tecnológicos en época incaica, aunque incorporando referentes visuales cuzqueños tales como las clepsidras y tridentes (Troncoso 2008). La ritualidad incaica en CACM, por tanto, reproduce principios básicos del Tawantinsuyu, pero en ella hay integración de elementos tradicionales locales, tales como el arte rupestre y una técnica arquitectónica que, si bien es nueva para la zona, no es una expresión pura de la arquitectura inca.

Finalmente, un aspecto interesante es que, si bien la organización espacial interna del sitio marca tres puntos diferentes en el recorrido, no existe una clara implementación arquitectónica para conformar segregaciones y jerarquizaciones internas. No se observan recintos con mayores condiciones de visibilidad, o diferencias de altura entre los sectores del sitio, situación que sí ocurre en otros lugares. Ello es solidario con las propuestas anteriores, en el sentido de que la organización espacial no se orienta a segregar a los sujetos en su interior, y por ende remite a un grupo social muy cercano en la dinámica del poder en cuyo seno no es necesario establecer tales distinciones. Éstas se revelan, sin embargo, cuando evaluamos la dinámica espacial del CACM a nivel regional.

\section{Dinámica espacial del Complejo Arquitectónico Cerro Mercachas en su contexto regional}

Una de las principales características del CACM es su ubicación sobre un notorio cerro que permite que sea un hito claramente discernible en el área. Específicamente, el cerro es visible desde toda la cuenca de San Felipe-Los Andes, a la vez que es po- 
sible visualizar toda esa área desde la cumbre del CACM, cubriendo en ambos casos un campo visual que abarca hasta los $20 \mathrm{~km}$. Esto le otorga al CACM una posición central dentro de lo que es la construcción material del paisaje de la zona durante el período Tardío. De hecho, no existe en la cuenca de San Felipe-Los Andes ningún otro asentamiento incaico con similares condiciones.

Esta presencia del CACM lo transforma en un hito espacial que semantiza el espacio local a partir de la monumentalidad de la arquitectura asociada al Estado Cuzqueño. A partir de tal condición de visibilización, el sitio establece una integración del espacio local que logra solucionar la escasa integración espacial que presenta el patrón de asentamiento disperso de las comunidades locales. Con su ubicación, el sitio es visible desde los diferentes asentamientos habitacionales de las comunidades locales que se distribuyen por las terrazas de la cuenca de San Felipe-Los Andes.

Esta estrategia espacial constituye otra adaptación a la situación local de una estrategia que aplica el Inca en otros espacios. Tanto en el Norte de Chile, como en el Noroeste Argentino, hay poblados amurallados de poblaciones locales en cuyo sector más alto el Inca establece una plaza y otras construcciones como kallankas o ushnus (p.e. Pucara de Turi en Norte de Chile, La Paya y Guitián en el Noroeste Argentino). Con tal acción, se hacen presentes en estos poblados los símbolos del estado, que son claramente visibles desde diferentes segmentos de estas aldeas. El patrón de asentamiento disperso de las poblaciones locales de Aconcagua, y por ende la ausencia de poblados o aldeas, lleva a que se reproduzca un mismo modelo espacial pero a una escala mayor: en este caso es la construcción de una instalación sobre un cerro la que permite esta amplia presencia visual del Tawantinsuyu.

En Aconcagua este patrón no se representa sólo por el CACM, sino también por las otras construcciones sobre cerro identificadas hasta el momento: Complejo Arquitectónico El Tártaro en la cuenca de Putaendo, Cerro La Cruz en el curso medio del valle y Cerro Mauco en el curso inferior (Figura 1). Cada uno de ellos es ampliamente visible en su contexto local, pero lo interesante es que no se da una intervisibilidad entre estas instalaciones arquitectónicas.

Dos puntos son relevantes al respecto. El primero es que, en contraposición a los supuestos más utilizados frecuentemente, la disposición de estos sitios no conforma una red visualmente interconectada de instalaciones en altura. Este argumento ha sido uno de los puntales para definir estos sitios como fortalezas, pero en este caso no se confirma y pensamos que ello no se debe a un sesgo de la investigación, pues las prospecciones sistemáticas efectuadas a lo largo del valle se han orientado fuertemente a la búsqueda de instalaciones arquitectónicas sobre cerros, inspeccionándose hasta la fecha sobre 30 cumbres. El segundo punto, al parecer más significativo que el control visual del valle, es que la lógica de estos sitios descansa en que se trata de lugares ampliamente visibles en el espacio, o mejor dicho, lugares claramente reconocibles desde los sitios de vivienda de las poblaciones locales.

A través de esta dinámica, los sitios incaicos sobre cerro establecen una intervención visual sobre el mundo construido y cotidiano de las poblaciones locales, volviendo siempre presente la ocupación incaica en el lugar. Esta intervención visual se refrenda también en que, siguiendo el ramal del camino incaico que viene desde la vertiente oriental de los Andes, el CACM es el primer hito visible previo al ingreso al valle. 
Esta disposición de CACM no sólo es significativa por estos atributos, sino porque, como ya lo adelantaran Stehberg y Sotomayor (1999), se ubica en un lugar donde se concentra una importante actividad ceremonial-funeraria de las poblaciones locales desde tiempos previos. A los pies del sitio se encuentra el cementerio de túmulos de Santa Rosa (piedemonte Sur) y el cementerio de El Sauce; frente al cerro está el cementerio de túmulos de Los Guindos y en las cercanías se han recuperado entierros aislados. De esta manera, el sitio se apropia de un espacio sagrado previo, imponiendo esta arquitectura en las proximidades de tal lugar, pero en una posición de mayor altura que todos esos cementerios.

Sin embargo, la ritualidad plasmada en el CACM no es una ritualidad aislada. Pensamos que se articula con otro sitio propio de las comunidades locales que se encuentra a sus pies: Cerro Paidahuen (Figura 2). En otros trabajos (Troncoso 2008), se ha propuesto que un conjunto muy particular de sitios de arte rupestre de la cuenca de Aconcagua se constituyen en espacios de agregación social, en particular plazas de las comunidades locales que funcionarían durante el período Intermedio Tardío y Tardío. Esto se fundamenta en que ellas presentan una alta cantidad de bloques intervenidos con grabados, sugiriendo un carácter reiterativo de las prácticas en ese espacio, una organización lineal basada en el recorrido según un eje Norte-Sur y principios de estructuración exclusivos como son la dualidad y cuatripartición (Troncoso 2008).

Cerro Paidahuen es un pequeño cerro isla ubicado en las proximidades del CACM, con una directa relación visual con éste, donde se han reconocido 211 bloques con grabados y que ha sido interpretado según el modelo mencionado en el párrafo anterior. En la conformación de este sitio, los bloques de petroglifos se orientan mayormente hacia el Norte $(68,3 \%)$, marcando de esta manera el recorrido a seguir, y hacia el CACM. La finalización del recorrido en el sitio acaba en un gran soporte plano que tiene tres características: 1) ser el único soporte oblicuo al suelo, lo que posibilita que una persona se desplace sobre su superficie, 2) que junto a él se crea un espacio suficiente para permitir la agregación de personas, cosa que el reducido ancho de la cima de Paidahuen no permitía previamente y 3) que en ese lugar se mantiene una relación visual directa con el CACM (Figura 8).

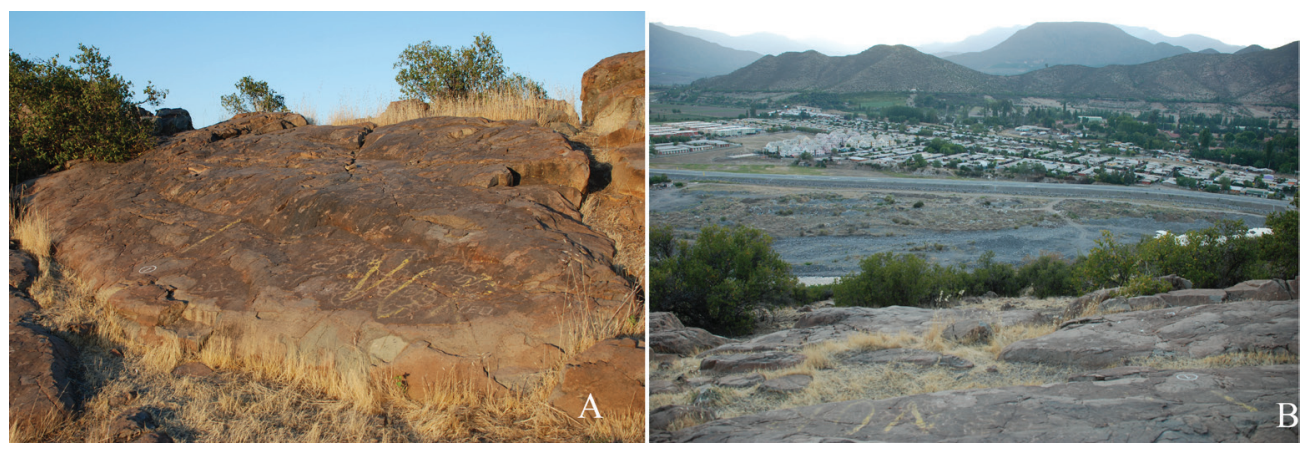

Figura 8: Bloque con petroglifos en el extremo sur del Cerro Paidahuen: a) vista general del bloque con los grabados, b) relación visual del bloque con el cerro Mercachas. 
Pensamos que esta estructura espacial permite proponer que nos enfrentamos a una ritualidad incaica que traspasa Mercachas para incluir a Cerro Paidahuen, que actuaría como una plaza y formaría parte de un complejo ceremonial asociado al CACM. De hecho, desde la roca final de Paidahuen no sólo se tiene una relación visual directa con CACM, sino que el panel con grabados se orienta nuevamente hacia la salida del sol en el solsticio de diciembre (Figura 9), lo cual es relevante, pues, no obstante el gran tamaño de la roca, los diseños se disponen en una esquina del panel que se alinea con el amanecer del mencionado solsticio. Las evidencias mencionadas llevan a pensar en una articulación que es a la vez segregación, con rituales realizados al menos para este momento del año en ambos sitios: mientras en el CACM el registro material sugiere un accionar de grupos más estrechamente asociados con el Estado, en Paidahuen se establecerían prácticas de agregación más bien de las poblaciones locales en un contexto de ritualidad en torno a Mercachas.

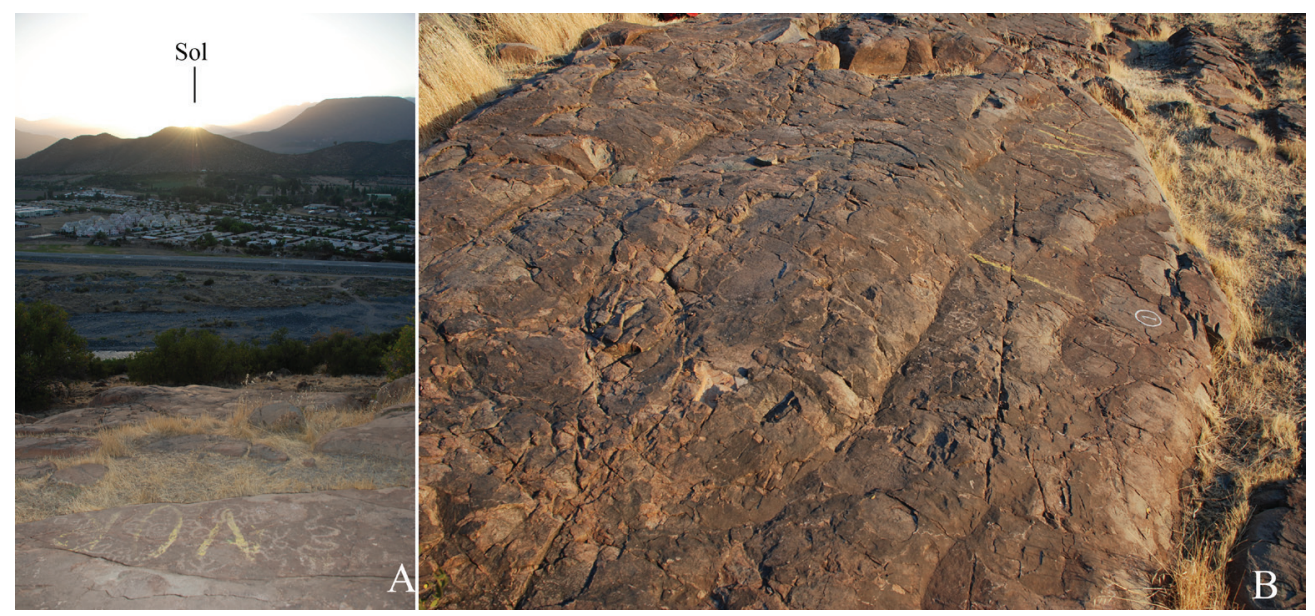

Figura 9: Orientación astronómica del bloque del extremo sur del Cerro Paidahuen: a) visibilidad desde el sector con grabados hacia la salida del sol en el solsticio de diciembre, b) vista lateral del bloque donde se observa la concentración de diseños en la esquina orientada hacia el solsticio.

Esta estrategia reproduciría los principios de inclusión/exclusión que han sido planteados para otros contextos incaicos en la región (Sánchez 2010). Por un lado, la dinámica ritual en el CACM incluiría el espacio de Aconcagua dentro del Tawantinsuyu con la realización de festividades en fechas importantes del calendario metropolitano incaico (Ziółkowski y Sadowski 1989); pero, a su vez, lo excluiría al no participar directamente de las principales actividades desarrolladas en la capital del Estado. Por otro lado, con su amplia condición de visibilización, la presencia espacial del CACM incluye a las diferentes comunidades de la zona en los rituales que suceden en su cumbre, en particular a los involucrados en el ceremonialismo de Cerro Paidahuen; pero, de nuevo, dado el reducido número de personas que se po- 
drían congregar en CACM, se produce una exclusión de las comunidades locales al no participar directamente en las actividades realizadas en el conjunto arquitectónico.

De esta manera, por encima de su dinámica como un sitio ritual, el CACM actúa como un recurso material político sobre el que el Tawantinsuyu establece prácticas y principios espaciales que segregan y diferencian a la población del valle, pero que a la vez la integran dentro de lo que es la dinámica ceremonial y calendárica del Tawantinsuyu. Es en ese doble juego donde el lugar pasa a ser un recurso central en el proceso de dominación incaica de la zona.

\section{Conclusiones}

Las propuestas planteadas en los apartados previos han permitido reconocer la dinámica de las prácticas espaciales realizadas en el interior del CACM, prácticas coherentes con un sitio de tipo ritual y a través de las cuales se reproducen principios cosmológicos y de estrategia política tradicionales del Tawantinsuyu. Pensamos que la expresión de estos principios es coherente con una dominación estatal mayormente centrada en la difusión de una ideología y la administración de recursos simbólicos orientados a la conformación de un paisaje incaico, por encima de un dominio fundado en un carácter de tipo más administrativo-burocrático y militar.

En efecto, aunque las hipótesis tradicionales optaron por privilegiar un interés minero y ganadero como fundamento de la ocupación inca en la zona, ocupando el CACM una función de vigilancia y control de este proceso, las evidencias arqueológicas no avalan tal escenario. Por un lado, no se han hallado hasta el momento, en toda la zona central de Chile, asentamientos asociados con la explotación minera, ni evidencias de una cadena operativa relacionada con el trabajo minero. Por otro, el registro faunístico ha revelado la ausencia de camélidos domesticados durante el período previo a la llegada del Inca, existiendo más bien guanacos en proceso de domesticación (Pavlovic et al. 2004). Por lo tanto, la ausencia de un gran stock de ganado, sumada a la ausencia de una práctica ganadera por parte de las poblaciones locales, hace difícil aceptar que ese hubiese sido un objetivo de la incorporación de este territorio al Tawantinsuyu.

En contraposición, y como lo demuestra la evidencia del CACM, es factible pensar en un modelo más centrado en el uso y manejo por parte del Estado de sus elementos simbólicos y religiosos con el fin de establecer una dominación e incorporación de las comunidades locales (Sánchez 2001-02). En este proceso, las poblaciones locales tendrían un importante nivel de agencia, como lo muestra en este caso la incorporación de arte rupestre en el complejo ceremonial inca.

La ausencia de conjuntos materiales asociados a poblaciones diaguita es relevante, por cuanto si estas son las poblaciones que operan la ocupación del territorio por el Tawantinsuyu, extraña su ausencia en este sitio. Sin embargo, los estudios realizados en otros asentamientos incaicos están convirtiendo este hecho en una constante (Pavlovic 2011), lo que lleva a pensar en una escasa agencia de estas poblaciones en este proceso. Por el contrario, la incorporación de arte rupestre local en CACM, sumado al hecho de que los análisis de activación neutrónica de la alfarería del sitio sugieren 
su producción en un contexto local, pero con una circulación en contextos exclusivos incas (Pavlovic 2011), abren la puerta a pensar que sean los mismos líderes locales los que hacen operativa la ocupación inca en el territorio, adoptando y adaptando los recursos materiales e ideológicos asociados con el Tawantinsuyu. Esta situación no ha de extrañar, pues no sólo se ha documentado en varias provincias del Estado (ver Alconini y Malpass 2010), sino también porque los resultados de la excavación de otros sitios incaicos en la zona ha mostrado un panorama muy similar al acá descrito: la presencia mayoritaria de cerámica con diseños y formas incas, pero producida localmente, con ausencia de alfarería diaguita o netamente incaica (Pavlovic 2011).

Esta utilización de elementos simbólicos en la ocupación del territorio no remite a un simple idealismo, sino que es complementaria y se articula con transformaciones en la base infraestructural de las comunidades locales. Este segundo aspecto se observa en que la magnitud de la construcción del CACM requiere necesariamente una importante inversión de mano de obra. Ambas son caras de una misma moneda, aunque no implican que la explotación minera-ganadera sea el sustento de la anexión de este territorio. Más bien, toda la dinámica implementada por el Tawantinsuyu en la zona se vertebraría con estos aspectos infraestructurales, pero supeditándolos a la cosmología y el complejo ceremonial señalados, siguiendo los principios que son propios de este Estado (Zuidema 2011) y que, como se sabe, son de una alta eficacia política (Dillehay 2002; Sánchez 2001-02; Ziółkowski 1997).

Agradecimientos: A todo/as aquello/as que colaboraron desinteresadamente en las diferentes campañas de terreno en el sitio y al editor de la revista por su colaboración en la mejora del texto. Este trabajo ha sido financiado por el proyecto FONDECYT 1090680 y la Wenner Gren Foundation a través de su proyecto Inca ritual activities and landscapes in Southern Andes. A.C.G.G. está contratado por el programa Ramón y Cajal del Ministerio de Economía y Competitividad de España.

\section{Referencias bibliográficas}

Acuto, Félix

2005 «The Materiality of Inca Domination: Landscape, Spectacle, Memory and Ancestors», en Global Archaeological Theory: Contextual Voice and Contemporary Thoughts, Pedro Paulo Funari, Andrés Zarankin y Emily Stovel, eds., pp: 221-235. Nueva York: Plenum Publishers.

Alconini, Sonia

2008 «Dis-embedded Centers and Architecture of Power in the Fringes of the Inka Empire: New Perspectives on Territorial and Hegemonic Strategies of Domination». Journal of Anthropological Archaeology 27: 63-81.

Alconini, Sonia y Michael Malpass

2010 Distant Provinces in the Inka Empire: Toward a Deeper Understanding of Inka Imperialism. Iowa: University of Iowa Press.

Ashmore, Wendy y Jeremy SABlofF

2002 «Spatial Orders in Maya Civic Plans». Latin American Antiquity 13: 201-215. 
BAUER, Brian y David DEARBorn

2003 Astronomía e Imperio en Los Andes. Cusco: Centro Bartolomé de Las Casas.

BAUER, Brian y Charles STANISH

2003 Las islas del Sol y de la Luna. Ritual y peregrinación en el lago Titicaca. Cusco: Centro Bartolomé de las Casas.

BELL, Catherine

1997 Ritual: Perspectives and Dimensions. Nueva York y Oxford: Oxford University Press.

Berenguer, José y Gloria CABello

2005 «Late Horizon Rock Art in the Atacama Desert?: A View from the Inka Road». Rock Art Research 22: 83-86.

BRAY, Tamara

2003 «To Dine Splendidly: Imperial Pottery, Commensal Politics and the Inca State», en The Archaeology and Politics of Food and Feasting in Early States and Empires, Tamara Bray, ed. pp: 93-142. Nueva York: Kluwer Academics.

Cereceda, Verónica

1988 «Aproximaciones a una estética andina: de la belleza al tinku», en Raíces de América: El mundo aymara, Xavier Albo, ed., pp. 283-363. Madrid: Alianza Editorial.

CoBen, Lawrence

2006 «Other Cuzcos: Replicated Theaters of Inka Power», en Archaeology of Performance: Theaters of Power, Community and Politics, Takeshi Inomata y Lawrence Coben, eds., pp. 223-260. Nueva York: Altamira Press.

Coleman, Simon y John Elsner

1994 «The Pilgrim's Progress: Art, Architecture and Ritual Movement at Sinai». World Archaeology 26 (1): 73-89.

Coros Cantín, Carlos y Carlos Coros Villca

1999 «El camino del Inca en la Cordillera de Aconcagua». Revista El Chaski 1: 1-64.

Criado Boado, Felipe y Patricia Mañana Borrazás

2003 «Arquitectura como materialización de un concepto. La espacialidad megalítica». Arqueología de la Arquitectura 2: 103-111.

Curatola Petrocchi, Marcos

2008 «La función de los oráculos en el imperio Inca», en Adivinación y oráculos en el mundo andino antiguo, Marcos Curatola y Mariusz Ziółkowski, eds., pp. 15-70. Lima: Instituto Francés de Estudios Andinos - Pontificia Universidad Católica del Perú.

Dillehay, Tom

2002 «El colonialismo Inka, el consumo de chicha y los festines desde una perspectiva de banquetes políticos». Boletín de Arqueología PUCP 7: 355-363.

Durán Serrano, Eliana y Carlos Coros Cantín

1991 «Un hallazgo incaico en el curso superior del río Aconcagua». Boletín del Museo Nacional de Historia Natural 42: 169-180.

Gallardo, Francisco y Flora Vilches

2001 «Arte rupestre en la época de dominación inca en el Norte de Chile», en Tras la huella del Inca en Chile, V.V.A.A., pp. 34-43. Santiago: Museo Chileno de Arte Precolombino. 
Garceau, Charles

2005 Lo cotidiano, lo simbólico y la integración del sitio Tambo Ojos de Agua en la región sur del Tawantinsuyu, Cordillera del Aconcagua. Memoria para optar al título de Arqueólogo, Departamento de Antropología. Santiago: Universidad de Chile.

GARCíA, Alejandro

1997 «Alcances del dominio incaico en el extremo suroriental del Tawantinsuyu (Argentina)». Chungará 29 (2): 195-208.

GASPARINI, Graziano y Luise Margolies

1977 Inca Architecture. Bloomington: Indiana University Press.

GonzÁlez, Carlos

2003 «Nuevos trabajos en Cerro Mercachas y algunos comentarios sobre su arquitectura», en Caracterización inicial del Período Intermedio Tardio en la cuenca superior del río Aconcagua, Informe proyecto Fondecyt 1000172, Daniel Pavlovic, comp., pp. 1-20. Santiago: CONICYT.

HeRnández Llosas, María Isabel

2006 «Inkas y españoles a la conquista simbólica del territorio Humahuaca: sitios, motivos rupestres y apropiación cultural del paisaje». Boletín del Museo Chileno de Arte Precolombino 11 (2): 9-34.

HiLlier, Bill y Julienne Hanson

1984 The Social Logic of Space. Cambridge: Cambridge University Press.

HYSLOP, John

1986 «Factors Influencing the Transmission and Distribution of Inka Cultural Materials Throughout Tawantinsuyu», en Latin American Horizons: A Symposium at Dumbarton Oaks, Stephen Rice, ed., pp. 337-356. Washington: Dumbarton Oaks Library and Collection.

1990 Inka Settlement Planning. Austin: University of Texas Press.

KendaLl, Ann

1976 «Descripción e inventario de las formas arquitectónicas inca». Revista del Museo Nacional 42: 13-96.

LEACH, Edmund

1993 Cultura y comunicación: La lógica de la conexión de los símbolos [1976]. Madrid: Siglo XXI Editores.

Letelier Cosmelli, Javiera

2009 Arquitectura en el Complejo Arquitectónico Cerro Mercachas. Práctica profesional. Facultad de Estudios del Patrimonio Cultural. Chile: Universidad Internacional SEK.

Llagostera Martínez, Agustín

1977 «Hipótesis sobre la expansión incaica en la vertiente occidental de los Andes Meridionales», en Homenaje al Dr. Gustavo Le Paige s.j., Hans Niemeyer, ed, pp. 203-218. Antofagasta: Universidad del Norte.

Moore, Jerry

1996a Architecture and Power in the Ancient Andes. Cambridge: Cambridge University Press. 
$1996 \mathrm{~b}$ «The Archaeology of Plazas and the Proxemics of Ritual». American Anthropologist 98 (4): 789-802.

MADRID, Jacqueline

1965 «Informe de la excavación de un cementerio de túmulos en la hacienda de Bellavista (San Felipe) y descripción de un aprendizaje arqueológico adquirido en la misma». Boletín de la Sociedad Arqueológica de Santiago 3: 45-65.

MonTt, Indira

2005 Vestimenta en la cultura visual tardía del desierto de Atacama. Memoria para optar al título de Arqueólogo. Departamento de Antropología. Santiago: Universidad de Chile.

MORRIS, Craig

1990 «Signs of Division, Symbols to Unity: Art in the Inka Empire», en Circa 1492: Art in the Age of Exploration, Jay Levenson, ed., pp. 521-528. Chicago: The Art Institute.

1995 «Symbols to Power: Styles and Media in the Inka State», en Style, Society and Person, Cristopher Carr y Jill Neitzel, eds., pp. 419-433. Nueva York: Plenum Press.

NiLes, Susan

1992 «Inca Architecture and the Sacred Landscape», en The Ancient Americas: Art from Sacred Landscape, Richard Townsend, ed., pp. 347-357. Chicago: The Art Institute.

OGBuRn, Dennis

2004 «Dynamic Display, Propaganda, and the Reinforcement of Provincial Power in the Inca Empire». Archeological Papers of the American Anthropological Association 14 (1): 225-239.

PARKIN, David

1992 «Ritual as Spatial Direction and Bodily Division», en Understanding Rituals, David de Coppet, ed., pp. 11-25. Londres: Routledge.

Pavlovic, Daniel

2006 La gente del valle de las rinconadas: uso del espacio y tradiciones tecnológicas durante el período Intermedio Tardio en el valle del río Putaendo. Memoria para optar al título de Arqueólogo, Departamento de Antropología. Santiago: Universidad de Chile.

2011 Las poblaciones locales y el Tawantinsuyu en la cuenca del río Aconcagua: Transformaciones socioculturales e ideológicas durante el periodo Tardio. Informe proyecto Fondecyt 1090680. Santiago: Conicyt

Pavlovic, Daniel y Esteban Rosende

2010 «Más cerca de las Wakas: la ocupación de cerros de mediana y baja altura durante el período Tardío en la cuenca superior del río Aconcagua», en Actas del XVII Congreso Nacional de Arqueología Argentina, tomo III-IV, pp. 1279-1284.

Pavlovic, Daniel, Andrés Troncoso, Rodrigo Sánchez y Paola GonzÁlez

2004 «Por cerros, valles y rinconadas: investigaciones arqueológicas en el valle del río Putaendo, cuenca superior del río Aconcagua». Chungará 36, volumen especial: 847-860. 
Rodríguez, Arturo, Ramón Morales, Carlos GonzÁlez y Donald JACKson

1993 «Cerro La Cruz: Un enclave económico administrativo incaico, Curso Medio del Río Aconcagua», en Actas del XII Congreso Nacional de Arqueología Chilena, vol. 2, pp. 201-222. Temuco: Sociedad Chilena de Arqueología

Rossen, Jack, María Teresa Planella y Rubén Stheberg

2010 «Archaeobotany of Cerro del Inga, Chile, at the Southern Inka Frontier», en Distant Provinces in the Inka Empire: Toward a Deeper Understanding of Inka Imperialism, Sonia Alconini y Michael Malpass, eds., pp. 14-43. Iowa City: University of Iowa Press.

SÁnchez Romero, Rodrigo

2001-02«El Tawantinsuyu salvaje en el Finis Terrae Australis (Chile Central)». Revista Chilena de Antropología 16: 87-127.

2004 «El Tawantinsuyu en Aconcagua (Chile Central)». Chungará 36 (2): 325-336.

SANGUINETTI, Norma

1975 «Construcciones indígenas en el cerro Mercachas (Depto. de Los Andes, Prov. de Aconcagua)». Anales del Museo de Historia Natural de Valparaíso 8: 129-139.

SCHOBINGER, Juan

2001 El santuario incaico del Cerro Aconcagua. Mendoza: Editorial de la Universidad Nacional de Cuyo.

SEPúlVEDA, Marcela

2004 «Esquemas visuales y emplazamiento de las representaciones rupestres de camélidos del Loa Superior en tiempos incaicos ¿Una nueva estrategia de incorporación de este territorio al Tawantinsuyu?». Chungará 36 (2): 439-452.

SiLva, Osvaldo

1985 «La expansión incaica en Chile: problemas y reflexiones», en Actas del IX Congreso de Arqueología Chilena, pp. 321-340. La Serena: Sociedad Chilena de Arqueología.

STEHBERG, Rubén

1976 La fortaleza de Chena y su relación con la ocupación incaica de Chile Central. Santiago: Publicación Ocasional del Museo Nacional de Historia Natural.

1995 Instalaciones incaicas en el norte y centro semiárido de Chile. Santiago: Dirección de Bibliotecas y Museo.

StehBerg, Rubén y Gonzalo Sotomayor

1999 «Cabis, guacas-fortalezas y el control incaico del valle de Aconcagua». Estudios Atacameños 18: 237-248.

TopIC, John

2008 «El santuario de Catequil: estructura y agencia, hacia una comprensión de los oráculos andinos», en Adivinación y oráculos en el mundo andino antiguo, Marco Curatola y Mariusz Ziółkowski, eds., pp. 71-96. Lima: Instituto Francés de Estudios Andinos - Pontificia Universidad Católica del Perú.

Troncoso, Andrés

2005 «Hacia una semiótica del arte rupestre de la cuenca superior del río Aconcagua, Chile central». Chungará 37 (1): 21-35.

2008 Arte rupestre en la cuenca del Aconcagua: formas, sintaxis, estilo, espacio y poder. TAPA 39. Santiago de Compostela: Instituto de Estudios Gallegos Padre Sarmiento (CSIC). 
Troncoso, Andrés, Daniel Pavlovic, Andrea Martínez, Félix Acuto, Rodrigo Sánchez y A. César GonzÁlez

2011 «Festines en Chile central: Desde tiempos preincaicos a época incaica». Manuscrito en posesión de los autores.

URZÚA, Paula

2008 Arte rupestre del Complejo Arquitectónico Cerro Mercachas. Práctica Profesional, Departamento de Antropología. Santiago: Universidad de Chile.

ZIÓŁKOwSKI, Mariusz

1997 La guerra de los wawqi, los objetivos y mecanismos de la rivalidad dentro de la elite Inka, siglos XV y XVI. Quito: Editorial Abya-Yala.

Zı́́ŁKOWSKi, Mariusz y Robert SADOwski

1989 «El calendario metropolitano inca», en Time and Calendars in the Inca Empire, Mariusz Ziółkowski y Robert Sadowski, eds., pp. 129-166. Oxford: BAR International Series 479.

ZuidemA, Tom

1991 La civilización inca en Cuzco. México: Fondo de Cultura Económica. 